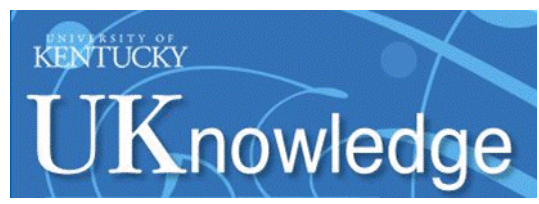

University of Kentucky

UKnowledge

\title{
Improving Student Dentist Competencies and Perception of Difficulty in Delivering Care to Children with Developmental Disabilities Using a Virtual Patient Module
}

\author{
Harold L. Kleinert \\ University of Kentucky, hklein@uky.edu \\ Carla Sanders \\ University of Kentucky \\ John Mink \\ University of Kentucky \\ David A. Nash \\ University of Kentucky, danash@uky.edu \\ Jeff Johnson \\ University of Kentucky
}

Follow this and additional works at: https://uknowledge.uky.edu/hdi_facpub

a next page for additional authors

Part of the Dentistry Commons, and the Medical Education Commons

Right click to open a feedback form in a new tab to let us know how this document benefits you.

\section{Repository Citation}

Kleinert, Harold L.; Sanders, Carla; Mink, John; Nash, David A.; Johnson, Jeff; Boyd, Sara; and Challman, Sandra, "Improving Student Dentist Competencies and Perception of Difficulty in Delivering Care to Children with Developmental Disabilities Using a Virtual Patient Module" (2007). Human Development Institute Faculty Publications. 1.

https://uknowledge.uky.edu/hdi_facpub/1

This Article is brought to you for free and open access by the Human Development Institute at UKnowledge. It has been accepted for inclusion in Human Development Institute Faculty Publications by an authorized administrator of UKnowledge. For more information, please contact UKnowledge@lsv.uky.edu. 


\title{
Improving Student Dentist Competencies and Perception of Difficulty in
} Delivering Care to Children with Developmental Disabilities Using a Virtual Patient Module

\author{
Notes/Citation Information \\ Published in Journal of Dental Education, v. 71, no. 2, p. 279-286.
}

Reprinted by permission of Journal of Dental Education, Volume 71, no. 2 (Feb. 2007). Copyright 2007 by the American Dental Education Association. http://www.jdentaled.org

\section{Authors}

Harold L. Kleinert, Carla Sanders, John Mink, David A. Nash, Jeff Johnson, Sara Boyd, and Sandra Challman 


\title{
Improving Student Dentist Competencies and Perception of Difficulty in Delivering Care to Children with Developmental Disabilities Using a Virtual Patient Module
}

\author{
Harold L. Kleinert, Ed.D.; Carla Sanders, R.N., M.S.; John Mink, D.M.D.; David Nash, \\ D.M.D., Ed.D.; Jeff Johnson, D.M.D.; Sara Boyd, M.A.; Sandra Challman, M.S.
}

Abstract: An interactive, multimedia, virtual patient module was designed and developed on compact disc (CD-ROM) to address the need for student dentists to increase their competence and decrease their perception of difficulty in caring for children with developmental disabilities. A development team consisting of pediatric dentistry faculty members, parents of children with developmental disabilities, an individual with a developmental disability, and educational specialists developed an interactive virtual patient case. The case involved a ten-year-old child with Down syndrome presenting with a painful tooth. Student dentists were required to make decisions regarding proper interactions with the child, as well as appropriate clinical procedures throughout the case. Differences in perceived difficulty level and knowledge change were measured, as well as the student dentists' overall satisfaction with the learning experience. Significant results were obtained in both perceived difficulty level and knowledge-based measures for student dentists. Participants reported overall satisfaction with the modules. Preparing student dentists to provide sensitive and competent care for children with developmental disabilities is a critical need within dentistry. This study demonstrated that an interactive, multimedia (CD-ROM), virtual patient learning module for student dentists is potentially an effective tool in meeting this need.

Dr. Kleinert is Executive Director, Interdisciplinary Human Development Institute, University of Kentucky; Ms. Sanders is Project Coordinator, Preservice Health Training Project, Interdisciplinary Human Development Institute, University of Kentucky; Dr. Mink is Professor of Pediatric Dentistry and Division Chief, College of Dentistry, University of Kentucky; Dr. Nash is Professor of Pediatric Dentistry, College of Dentistry, University of Kentucky; Dr. Johnson was Director, Advanced Education in Pediatric Dentistry, College of Dentistry, University of Kentucky and is currently in pediatric practice in Danville, KY; Ms. Boyd is Project Research Assistant, Preservice Health Training Project, Interdisciplinary Human Development Institute, University of Kentucky; and Ms. Challman is Manager of Instructional Technology, College of Dentistry, University of Kentucky. Direct correspondence and requests for reprints to Dr. Harold L. Kleinert, Executive Director, Interdisciplinary Human Development Institute, 126 Mineral Industries Bldg., University of Kentucky, Lexington, KY 40506; 859-257-3045 phone; hklein@uky.edu.

This project was supported in full by a grant from the Kentucky Council on Developmental Disabilities. However, the opinions expressed are strictly those of the authors and do not necessarily reflect the opinions of the supporting organization.

Key words: dental education, developmental disabilities, Down syndrome, special needs dentistry, multimedia instruction, computer-assisted learning

Submitted for publication 6/17/06; accepted 10/20/06

$\mathrm{T}$ Trends in deinstitutionalization, as well as improving life expectancies, have increased the number of individuals with developmental disabilities residing in the community and requiring basic community services. ${ }^{1,2}$ Access to competent medical and dental care is at the forefront of these basic needs, yet the dearth of willing and competent health professionals persists as an obstacle to access. ${ }^{3,4}$ The problem of disparities in access to quality medical and dental care has been consistently reported in both studies of health professionals training and attitudes ${ }^{2}$ and studies of family and individual experiences in accessing care. ${ }^{5}$ Problems of health disparity at the national level were noted in the 2001
U.S. surgeon general's conference and report, Closing the Gap: A National Blueprint for Improving the Health of Individuals with Mental Retardation. ${ }^{6}$

It is well established that developmental disabilities have a significant impact on the overall health of individuals, including children. Accommodations are often necessary in the provision of care, and serious dental and medical conditions may arise as secondary effects of the developmental disability. ${ }^{7}$ For example, one of the most common forms of developmental disabilities, Down syndrome, frequently presents with oral health concerns including bruxism, periodontal disease, gingivitis, and microdontia. ${ }^{8}$ Pediatric dental patients with Down syndrome may require antibiotic 
prophylaxis; adjustments in positioning may also be necessary if atlantoaxial instability is present. Additionally, these patients may present with craniofacial abnormalities that potentially affect occlusion. ${ }^{9}$

Research findings, however, suggest that the majority of student dentists are not being adequately prepared to meet the clinical needs of children and/or adults with special needs, such as Down syndrome. ${ }^{10-12}$ In a 2004 study of U.S. dental schools by Wolff et al., nearly 70 percent of third- and fourth-year student dentists reported five hours or less of classroom instruction in the care of persons with mental retardation, and 60 percent of students reported that they had "little to no confidence in providing care" for persons with mental retardation. ${ }^{11}$

The 2001 U.S. surgeon general's report identified goals for improving the health of individuals with mental retardation, including that of training health care professionals in caring for adults and children with mental retardation. ${ }^{6}$ The American Academy of Developmental Medicine and Dentistry (AADMD) was established in May 2002 partly in response to the surgeon general's report. The AADMD originated as a national, professional organization of physicians and dentists with expertise in the area of special needs who were committed to improving medical and dental care for individuals in this population. The organization has developed a model of education to eliminate barriers for patients with developmental disabilities; this model involves the creation of consistent, efficient instruction that may be adapted and infused into the curriculum of any medical or dental school. ${ }^{10}$

The American Dental Association (ADA) responded to identified gaps in professional training by revising its dental education accreditation standards to specifically address individuals with developmental disabilities. In 2002, the ADA adopted a resolution supporting access to oral health care for persons with special needs, which included pledging support for necessary legislation to effect change. ${ }^{13}$ The Accreditation Standards for Dental Education Programs addresses the need for graduates to demonstrate competency in the care of individuals with special needs. These individuals include (but are not limited to) people with developmental disabilities, complex medical problems, and significant physical limitations.

In August 2003, the results of an extensive study of dental and medical educational progress in developmental disabilities, or special needs patients, were described in the results of the Curriculum Assessment of Needs (CAN) Project through the University of Lou- isville. ${ }^{14}$ The results of seventeen surveys, conducted with medical and dental school deans, residency program directors, students, and patient advocacy groups, again documented the need in this area. Fifty-three percent of dental school deans and 60 percent of dental students felt that most graduates are not competent to care for patients with intellectual disabilities. The results of the CAN Project further demonstrated that although the majority of student dentists ( 75 percent) reported interest in treating patients with intellectual disabilities, 51 percent reported receiving no clinical experience in this area. Furthermore, 50 percent of dental school deans and 53 percent of residency program directors surveyed reported their programs were not providing appropriate clinical training in the area of developmental disabilities.

Clearly, much remains to be done in preparing general dentists to care for patients with developmental disabilities. The lack of availability of an adequate patient pool to practice clinical skills has been cited as one barrier to the development of proficiency in this practice area. ${ }^{12,15}$ For many developmental disabilities (e.g., Down syndrome, deaf-blindness), students may simply not have the opportunity to provide treatment during their training.

Interactive, multimedia, computer-based, virtual patient instruction provides an alternative to hands-on experience and has demonstrated consistent efficacy in a variety of educational domains, including clinical training in the health professions. ${ }^{16-18}$ For example, Frisby et al. found that a computer-based multimedia program consisting of an infant patient encounter was more effective in teaching physical examination skills to medical residents than routine didactic instruction..$^{18}$ Interactive, computer-based, multimedia, virtual patient instruction offers several advantages over traditional instruction. Virtual patient encounters offer students the opportunity to practice clinical decision-making skills in an environment that poses no danger to either student or patient. ${ }^{19,20} \mathrm{An}$ interactive format typically allows students to learn at their own pace, ${ }^{16}$ and the format provides for prompt feedback, which supports student metacognition. ${ }^{19}$ Metacognition, or systematically reflecting upon one's own thinking and problem-solving skills, is a key feature that distinguishes more competent from less competent learners. ${ }^{21}$

This study attempted to demonstrate whether a virtual patient program, involving a dental visit for a child with Down syndrome, would result in increased knowledge in caring for individuals with 
developmental disabilities and less perceived difficulty in doing so. The null hypothesis was that after the implementation of this instructional methodology, there would be no difference in pre- and post-test scores when third-year student dentists were assessed regarding their cognitive knowledge and perception of difficulty in caring for children with developmental disabilities. A final concern was whether student dentists would report satisfaction and ease of use with the interactive, multimedia, computer-based, virtual patient learning format.

\section{Materials and Methods}

The Preservice Health Training Project was funded by the Kentucky Council on Developmental Disabilities, in collaboration with the University of Kentucky Interdisciplinary Human Development Institute and the University of Kentucky College of Dentistry. The project included the development of two interactive, multimedia, virtual patient modules specifically targeting student dentists (a pediatric and an adult case). Our study examines the effectiveness of the pediatric module.

The purposes of the dental modules were to 1) decrease student dentists' perceived sense of difficulty when working with children and adults with developmental disabilities, and 2) increase students' knowledge base regarding the clinical issues that often present in patients with developmental disabilities. The modules were constructed to simulate an actual patient encounter, in which the student dentist would have to make decisions throughout the course of the case.

A development team was formed to guide the creation of the pediatric dentistry module. The team consisted of three pediatric dentistry faculty members and the instructional design specialist from the College of Dentistry, three parents of children with developmental disabilities, an adult with a developmental disability, technology consultants, and two experts in the field of developmental disabilities. Parents and consumer team members provided examples of how families and individuals with developmental disabilities could be empowered as full partners in their dental care, as well as specific accommodations and communication strategies that they had found successful in their own experience. Learning objectives were initially identified and aligned with objectives addressed by the existing curriculum for student dentists in the College of Dentistry. Figure 1 shows the knowledge competencies to be achieved by participating in the module.

An interactive, multimedia, virtual patient model for CD-ROM was selected as the instructional design. The team first decided upon a scenario to illustrate the learning required for managing a dental

1. Characterize the physical, cognitive, emotional, and oral circumstances typically associated with a child having Down syndrome.

2. Prepare his/her practice staff for the care of the child with special needs.

3. Communicate effectively with parents about how the child's overall health status affects the provision of dental care.

4. Prepare for initial diagnosis of a child with special needs.

5. Communicate effectively with parents on how the child's disability impacts the course of care for the child.

6. Employ effective management techniques to gain a child's cooperation and provide the required care.

7. Communicate effectively with parents about how the child's emotional and cognitive development affects the provision of dental care.

8. Appropriately prepare the child for what is coming next during the course of treatment.

9. Effectively query the parent as to what approaches to gaining cooperation from the child have been found to be effective.

Figure 1. Student dentist knowledge competencies 
visit for a child with Down syndrome complaining of a painful tooth, who was accompanied on the visit by his father. The team guided the script development, and a family with a child with Down syndrome was selected to play the role of father and pediatric patient. That family then joined the development team and provided guidance in terms of how their son would respond to specific situations in the context of the script, which would reflect an actual pediatric visit.

The team developed an instructional system of Information Point-Decision Point-Video Decision Demonstration (IP-DP-VD) units that were employed throughout the interactive case. In each of these IP-DP-VD units, an Information Point, a concise one-page summary of pertinent information (e.g., special dentistry considerations for a child with Down syndrome; communication and behavioral management strategies) preceded a question directly related to that information. These Information Point questions were designed to be a quick review of that case-specific content. Information Points were then typically followed by Decision Point questions, which required student dentists to indicate how they would proceed in caring for and communicating with the child and in discussing the child's care and treatment plan with his father. Both Information and Decision Points were interspersed throughout the case and required student dentists to apply their knowledge or skill to the presenting situation. After each Information and Decision Point, the student was provided immediate feedback on his or her choice. A video clip demonstrating the technique or teaching point followed to visually reinforce the learning. The case consisted of a series of ten high-resolution, full-screen video clips, representing the sequence of an actual office visit, exam, cleaning, and brushing demonstration for a pediatric patient with Down syndrome. Information Points and Decision Points were developed to specifically address the module objectives. Additional module content was provided through the use of links to resource documents containing more in-depth material.

The father who participated on our development team played the role of the father in the video, his ten-year-old son with Down syndrome played the child, and the pediatric faculty member with the most experience in caring for patients with developmental disabilities played the role of the general dentist. Finally, to provide the student dentist with a sense of the virtual family's real-life experiences in seeking dental care for their son, an audio-recorded question and answer section was included at end of the module in which the father related effective strategies that have worked for his son, as well as examples of care that was less than adequate.

Upon completion of the module's development, the project sought and received approval by the university's Institutional Research Board to conduct a study of its effectiveness with third-year student dentists.

A total of fifty-one student dentists from the College of Dentistry participated in the effectiveness study. While the completion of the module was required in the students' pediatric dentistry courses, participation in the research aspect of the project was voluntary; students did not have to submit their pre/post-tests for analysis by the researchers. All fifty-one students returned their packets. Fifty students (98 percent) completed both the pre- and post-tests for the perceived difficulty measure, and forty-nine students ( 96 percent) completed both the pre- and post-knowledge measures. Of the fifty-one students, twenty-four were females (47.1 percent) and twenty-seven were males ( 52.9 percent). All fiftyone students were third-year students. The majority of students (52.9 percent) were twenty-five years of age or under, with 33.3 percent between the ages of twenty-six and thirty, and 13.8 percent over the age of thirty-one.

The development team constructed the evaluation instruments used in the module's effectiveness study. The Disability Situations Inventory (DSI) was developed to measure student dentists' perceived sense of difficulty in addressing dental needs of individuals with developmental disabilities before and after completing the module. Items were developed based on the team's judgment of potentially difficult situations student dentists could encounter in caring for children with developmental disabilities. Both dental faculty and the family members contributed to the development of the final set of items. The situational items were also selected to reflect the competencies identified in Figure 1. The DSI contained eight items or potential situations for students to self-rate on a five-point Likert scale, with higher numbers indicating greater perceived difficulty. The eight items in this scale are presented in Figure 2.

The pre- and post-test of knowledge consisted of fifteen multiple choice items based upon the content of the module. Knowledge items clustered in the areas of 1) specific dental/oral health issues that may impact individuals with Down syndrome (e.g., oral-facial features of children with Down syndrome; frequent alterations in dentition, delayed eruption 
Some situations dentists encounter may be difficult to handle, awkward, or embarrassing. Please evaluate how difficult you would find each of the following situations and circle the number that corresponds to the difficulty on a scale of 1 to 5 , with 5 the most difficult.

1. Conducting an oral exam for a child with Down syndrome whose speech you have great difficulty understanding.

$\begin{array}{ccccc}1 & 2 & 3 & 4 & 5 \\ \text { Not Difficult } & & & & \text { Difficult }\end{array}$

2. Talking with the parents of a child with Down syndrome who adamantly refuse sedation for their child.

$\begin{array}{ccccc}1 & 2 & 3 & 4 & 5 \\ \text { Not Difficult } & & & & \text { Difficult }\end{array}$

3. Treating a six-year-old child with Down syndrome who is fearful and squirms when you ask him to open his mouth so you can check his teeth.

$\begin{array}{ccccc}1 & 2 & 3 & 4 & 5 \\ \text { Not Difficult } & & & & \text { Difficult }\end{array}$

4. Recognizing the common oral/dental findings that may present in a child with Down syndrome.

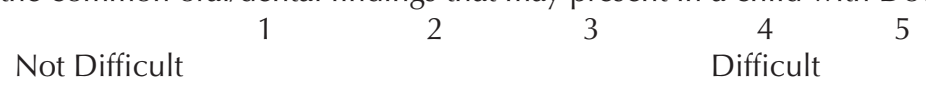

5. Building rapport with a twelve-year-old boy having Down syndrome who has never received dental treatment.

$\begin{array}{ccccc}1 & 2 & 3 & 4 & 5 \\ \text { Not Difficult } & & & & \text { Difficult }\end{array}$

6. Demonstrating effective oral hygiene to a ten-year-old child with Down syndrome who does not appear to be doing a good job with brushing and flossing his teeth.

$\begin{array}{ccccc}1 & 2 & 3 & 4 & 5 \\ \text { Not Difficult } & & & & \text { Difficult }\end{array}$

7. Clinical management of a child with a developmental disability whose teeth show significant effects of bruxism.

$\begin{array}{ccccc}1 & 2 & 3 & 4 & 5 \\ \text { Not Difficult } & & & & \text { Difficult }\end{array}$

8. Treating a child with a cognitive disability who does not appear to understand your verbal instructions about what is going to happen next in the visit.
1
Not Difficult
2
3
4
5
Difficult

Figure 2. Disability situations inventory

of teeth, and increased occurrence of periodontal disease in children with Down syndrome - a total of six items);2) specific issues relating to communicating with children with Down syndrome (e.g., typically higher receptive than expressive language skills, importance of conversing directly with the child, anatomical differences that may result in poor articulation of speech - a total of six items); and 3) 
overall knowledge of health issues in Down syndrome and how those factors might influence dental care (e.g., frequent cardiac defects requiring antibiotic prophylaxis, possible presence of atlantoaxial instability, and higher incidence of leukemia — a total of three items).

A Usability Scale asked participants to rate 1) the need for this program for both student dentists and practicing dentists; 2) general ease of use and navigational features; 3 ) accuracy and comprehensiveness of the content of the program (from the student's perspective); 4) the value of interacting with the virtual patient in providing care; 5) the value of the additional elements of the module, including the information points and resource documents; and 6) any technical problems encountered with use of the compact disc. The content and format of the Usability Scale was adapted from the scale for Decision-Making in Dental Management Cases. ${ }^{22}$ All data were analyzed using the Statistical Package for Social Sciences (SPSS).

\section{Results}

Of the fifty-one students who participated in the study, fifty students completed both the pre- and post-Disability Situations Inventory. For these fifty students, the mean pre-test score was $26.3, S D=4.4$, out of a possible maximum score of 40 . This reflected an average pre-test rating of 3.3 for each of the eight items. The mean post-test score was $20.3(S D=5.0)$ with an average item rating of 2.5 , with lower scores indicating less perceived difficulty. Univariate analysis via paired sample t-tests demonstrated a significant decrease in perceived difficulty for representative situations after completion of the interactive module; $t(49)=6.74, p<.0001, d=0.95$.

Of the fifty-one students in the study, forty-nine completed both the pre- and post-knowledge tests. Mean scores on the fifteen-item test were $M=6.7$ and $S D=2.1$ for the pre-test and $M=10.7$ and $S D=2.5$ for the post-test, representing a change from 45 percent to 71 percent correct (or a relative gain of 59.2 percent over the pre-test measure). Paired sample t-tests demonstrated that gains in knowledge were significant, $t(48)=-10.12, p<.001, d=1.45$, with thirteen of the fifteen individual items reaching significance at the $p=.05$ level.

All fifty-one students completed the Usability Scale. In addition to soliciting information about specific aspects of "user friendliness" and navigability of the CD-ROM module, the Usability Scale ${ }^{22}$ also functioned to evaluate the CD-ROM module's overall usefulness as an instructional tool. Students agreed on the need of the program for themselves: their mean rating of 3.5 fell between "some need" (a rating of 3 on the scale) and "needed" (a rating of 4 on the scale). Interestingly, students rated the need for practicing dentists as slightly higher: $\mathrm{M}=3.7, \mathrm{SD}=.8$, on the 5-point scale. Mean ratings for the Usability Scale (on a Likert rating of "1" to "5" with higher scores more positive) are illustrated in Table 1.

\section{Discussion}

Researchers have consistently found that student dentists are not prepared to fully meet the communication and dental care needs of their pediatric patients with developmental disabilities. ${ }^{10,11}$ Providing student dentists with adequate training in this area is important, yet it is not always possible to ensure that students will receive the required clinical experiences to learn how to effectively accommodate the needs of patients with developmental disabilities. This module represents one educational tool to provide student dentists with an initial experience that simulates the demands of the treatment setting, while focusing on both essential problem-solving and dentist-patient communication skills.

The purpose of our study was to assess student dentists' cognitive knowledge about treating children and adolescents with developmental disabilities, as well as their perceived sense of difficulty in treating these patients before and after intervention (student viewing and interaction with the educational material). Significant changes were found in both knowledge and perceived difficulty levels for students as a result of completing the module.

The user-friendliness of the interactive, multimedia, virtual patient CD-ROM was also examined as a teaching tool for student dentists. Students rated the modules as easy to use, with clear navigation aids, and important to their overall training. This study supports the earlier findings of Jeffries, ${ }^{16}$ Garrett and Callear, ${ }^{17}$ and Frisby et al. ${ }^{18}$ that computerbased learning experiences can be a useful adjunct for clinical training. The results suggest this type of tool may represent one effective strategy for addressing accreditation standards in relation to pediatric patients with special needs. 


\section{Limitations}

A key limitation to this study was a reliance on indirect measures of knowledge and perceived difficulty level for the participating student dentists, and not upon direct assessment of actual change in dentist-patient encounters. Assessment of actual dentist-patient encounters was not within the scope of the present project, but ultimately provides the best evidence for the validity of an interactive teaching tool.

Second, a previously validated measure of perceived difficulty in dealing with similar situations was not used, as we could not identify any existing instrument that could measure student dentists' perception of difficulty within the desired domain. As a result, scenarios were developed based upon the real-life perspectives of the parents and individual with disability who were members of the team, with assistance from the dental faculty members.

Third, while the response rate for this study was good for voluntary student participation in an effectiveness study, with all student dentists returning their packets and all but one student having analyzable pre- and post-test data, it cannot be stated with certainty that similar results would be found with students at other dental schools. Further, since it was desirable for all students in the third-year course to complete the module, a control group was not utilized. This is an important limitation, and thus it cannot be said that the reported improvements in knowledge and comfort level are entirely attributable to module completion.

Fourth, while our usability scale included questions that student dentists were quite competent to answer (e.g., ease of use and navigation, clarity of the content, importance of these modules to their education), we included at least two items that were problematic for students to judge: the accuracy and comprehensiveness of the content. Thus, the ratings for these two items, while positive from a student perspective, should be interpreted very guardedly.

Finally, students were able to answer only 71.0 percent of the questions correctly on the post-test. While this represents a significant improvement over the mean of 44.6 percent on the pre-test, student performance on the post-test may have improved further if post-test performance had been included as part of students' evaluation for a grade in the course. Instead, since this was a pilot study, students were evaluated only on whether they completed the module, and not on their actual score.

\begin{tabular}{ll} 
Table 1. Usefulness and navigation ratings & \\
Item description & $\begin{array}{c}\text { Mean and } \\
\text { Standard } \\
\text { Deviation }\end{array}$ \\
\hline Need for program for self & $3.5 \pm .9$ \\
Need for program for other students & $3.5 \pm .8$ \\
Need for program for practicing dentists & $3.7 \pm .8$ \\
Knew how to start using the program & $4.0 \pm 1.0$ \\
Knew how to get information & $3.7 \pm 1.0$ \\
Assistance was appropriate & $3.9 \pm 1.0$ \\
Knew how to interact with each item & $3.9 \pm .9$ \\
Effectiveness of navigational buttons & $4.0 \pm .9$ \\
Overall ease of navigability & $3.8 \pm .8$ \\
Accuracy of content & $4.1 \pm .8$ \\
Comprehensiveness of content & $4.1 \pm .8$ \\
Helpfulness of resource documents & $3.8 \pm .9$ \\
Resource section navigability & $3.9 \pm .8$ \\
Resource section contribution to module & $3.9 \pm .8$ \\
Contribution of video clips & $4.2 \pm .9$ \\
Sound quality & $3.9 \pm 1.0$ \\
Presentation of onscreen text & $3.9 \pm .9$ \\
Functionality and usefulness of web links & $3.6 \pm .9$ \\
Contribution of Decision Points to learning & $3.7 \pm .8$ \\
Contribution of Information Points to learning & $3.9 \pm .8$ \\
Beneficial for training first-year students & $2.9 \pm 1.3$ \\
Beneficial to training second/third-year students & $4.1 \pm .9$ \\
Assistance for practicing dentists & $4.0 \pm .9$ \\
&
\end{tabular}

\section{Implications}

Teaching student dentists the knowledge and communication skills to work with pediatric patients with developmental disabilities is not an easy task, especially given that student dentists will not always have access to these patients in their clinical training. While our tool was designed to teach student dentists about the dental needs of pediatric patients with Down syndrome, it is suggested that the communication, modeling, and other strategies for adapting treatment procedures for this population may well generalize across pediatric patients with other developmental disabilities. Future research is needed to determine the most effective instructional methods for ensuring that student dentists are equipped with skills required for working with the broad range of developmental disabilities they may expect to encounter in future practice. 


\section{REFERENCES}

1. Cole JF. Call for collaborative and integrated health services, physician training, and inter-systems consultation. Exceptional Parent Magazine, September 2004:85-8.

2. Waldman HB, Perlman SP. Preparing to meet the dental needs of individuals with disabilities. J Dent Educ 2002;66:82-5.

3. Steinberg BJ. Issues and challenges in special care dentistry. J Dent Educ 2005;69:323-4.

4. Bonito AJ. Executive summary: dental care considerations for vulnerable populations. Spec Care Dent 2002;22:5S$10 \mathrm{~S}$.

5. Betz CL, Baer MT, Poulsen M, Vahanvaty U, Barc M, Haddad Y, et al. Secondary analysis of primary and preventive services accessed and perceived service barriers by children with developmental disabilities and their families. Issues Compr Pediatr Nurs 2004;27:83-106.

6. Closing the gap: a national blueprint for improving the health of individuals with mental retardation. Report of the Surgeon General's Conference on Health Disparities and Mental Retardation. Washington, D.C.: U.S. Department of Health and Human Services, February 2001.

7. Edelstein BL. Dental care considerations for young children. Spec Care Dent 2002;22:11S-25S.

8. Pilcher E. Dental care for the patient with Down syndrome. Downs Syndr Res Pract 1998;5:111-6.

9. National Institute of Dental and Craniofacial Research. Practical oral care for people with Down syndrome, 2005. At: www.nidcr.nih.gov/nidcr.nih.gov/Templates/CommonPage. aspx?NRMODE=Publis. Accessed: June 15, 2006.

10. Fenton SJ, Hood H, Holder M, May PB Jr, Mouradian WE, et al. The American Academy of Developmental Medicine and Dentistry: eliminating health disparities for individuals with mental retardation and other developmental disabilities. J Dent Educ 2003;67:1337-44.

11. Wolff AJ, Waldman HB, Milano M, Perlman SP. Dental students' experiences with and attitudes toward people with mental retardation. J Am Dent Assoc 2004;135: 353-7.
12. Waldman H, Fenton SJ, Perlman SP, Cinotti DA. Preparing dental graduates to provide care to individuals with special needs. J Dent Educ 2005;69:249-54.

13. American Dental Association, Commission on Dental Accreditation. Accreditation standards for dental education programs, 2006. At: www.ada.org/prof/ed/accred/standards/predoc.pdf. Accessed: May 3, 2006.

14. Joseph P. Kennedy, Jr. Foundation for the Benefit of Persons with Intellectual Disabilities. Curriculum assessment of needs project, 2005. At: northamerica.specialolympics. org/research/documents/CAN_Survey.ppt\#257,2,Purpose \%20of\%20CAN\%20Project. Accessed: May 3, 2006.

15. Ferguson FS, Berentsen BJ, Marinelli RD, Richardson PS. A predoctoral program in dental care for the developmentally disabled. J Dent Educ 1990;54:576-8.

16. Jeffries PR. Development and testing of a hyperlearning model for design of an online care course. J Nurs Educ 2005;44:366-72.

17. Garrett BM, Callear D. The value of intelligent multimedia simulation for teaching clinical decision-making skills. Nurse Educ Today 2001;21:382-90.

18. Frisby AJ, Lane JL, Carr AM, Ross E, Gottleib RP. Development and evaluation of an interactive multimedia clinical skills teaching program designed for the pediatric clerkship. Teach Learn Med 2006;8:18-21.

19. Zary N, Johnson G, Boberg J, Fors UGH. Development, implementation, and pilot evaluation of a web-based virtual patient case simulation environment-Web-SP. BMC Med Educ 2006;6:1-17.

20. Gordon JA, Wilkerson WM, Shaffer DW, Armstrong EG. "Practicing" medicine without risk: students' and educators' responses to high-fidelity patient stimulation. Acad Med 2001;76:469-72.

21. National Research Council. Knowing what students know: the science and design of educational assessment. Washington, DC: National Academy of Sciences, 2001.

22. Fleming J. Decision-making in dental management cases. Lexington, KY: ORCCA Technology, Inc., 2001. 